\title{
Is History of Suicidal Behaviour Related to Social Support and Coping Skills in Patients with Bipolar-I Disorder?
}

\author{
Maryam Mazaheri ${ }^{1}$, Banafshe Gharaee ${ }^{1, *}$, Amir Shabani ${ }^{2}$, Mozhgan Lotfi ${ }^{1}$ \\ ${ }^{1}$ Tehran Institute of Psychiatry, School of Behavioral Sciences and Mental Health, Iran University of Medical Sciences, Tehran, Iran \\ ${ }^{2}$ Mental Health Research Centre, Mood Disorders Research Group, Iran University of Medical Sciences, Tehran, Iran
}

Email address:

gharraee.b@iums.ac.ir (B. Gharaee)

${ }^{*}$ Corresponding author

\section{To cite this article:}

Maryam Mazaheri, Banafshe Gharaee, Amir Shabani, Mozhgan Lotfi. Is History of Suicidal Behaviour Related to Social Support and Coping Skills in Patients with Bipolar-I Disorder? European Journal of Preventive Medicine. Vol. 5, No. 5, 2017, pp. 65-70. doi: 10.11648/j.ejpm.20170505.13

Received: July 14, 2017; Accepted: July 19, 2017; Published: August 24, 2017

\begin{abstract}
Introduction: The aim of the present study is to evaluate role of Coping Styles and Social Support as predictive variables with respect to suicide attempt of patient with bipolar disorder (BD) type-I. Materials and Methods: Via random sampling method, 120 patients in Hazrat e Rasoul General Hospital and Iran Psychiatric Hospital were chosen as statistical sample of current study. BD type-I diagnosis was confirmed after assessment of psychiatrist via SCID. After acquiring written consent forms, patients answered to Copying Skill Questionnaire (CSQ) and Social Support Appraisals Questionnaire (SSAQ). Obtained data were assessed via Logistic Regression Analysis in SPSS-19. Results: Results showed that only social support can be used as predictive variable regarding forecasting suicide attempts of BD type-I. Conclusion: Due to predictive role of social support, clinician should be cognizant regarding educating patients and their family regarding benefits of social support and accordingly they should tailor proper therapeutic method for this group of patients.
\end{abstract}

Keywords: Bipolar Disorder Type-I, Coping Skill, Suicidal Attempt, Social Support

\section{Introduction}

Mood disorders are considered major burden on societies' health sectors; among mood disorders bipolar disorder is still considered as debatable group of disorders among clinicians and health authorities, and it is considered as prominent public health problem. Prevalence of BD type-I has been reported as 3.9 [1] percent in American population with range between 1.5 to 6.0 percent in general population [2]. Bipolar disorder is a chronic, relapsing illness characterized by recurrent episodes of manic or depressive symptoms, with intervening periods that are relatively (but not fully) symptom-free. Onset occurs usually in adolescence or in early adulthood, although onset later in life is also possible [3]. Psychotropic is considered as gold standard approach regarding treatment of bipolar disorder; aside from aforementioned approach various studies have highlighted role of CBT as promising psychotherapeutic approach regarding this malady. More pharmacologic options are now available, and psychoeducation, self-help, and psychotherapy (individual, couple, and family) interventions are frequently utilized [4].

Bipolar disorder tends to be one of the most chronic, sever and relapsing disorder among psychiatric disorders. In contrast to novel pharmacologic achievements, these patients experience high level of relapse and admitting to psychiatric hospital and this malady is still considered as one of the leading cause of death and morbidity and malfunctioning among afflicted individuals [5]. Prevalence of this disorder is $2 / 4 \%$ worldwide [6]; this trend in Iran is $1 \%$ [7]. Comparing bipolar patients and healthy individuals lead us to this premise that suicide is commonplace behavior among this group of people [8]. Suicide rate among BD type-I is between $10-18 \%$ [9].

To now, various studies have studied factors related to suicidal behavior among bipolar patients. However, few 
studies have discussed psychological dimensions related to suicidal behavior among this group of patients. Psychological factors may protect afflicted from various aspects of this disorder.

Social support is one the protective aspect with respect to decreasing incidence of suicidal behavior. Social support is "caring, love, respect, comfort and help offered by other people/groups to an individuals" [10].

Studart et al. (2016) reported that bipolar patients tend to benefit from social support less than normal people. Lower level of social support may have various consequences for these patients [11]. Patients with less social support may need more time for remission and may experience higher level of depression [12]. Furthermore, low social support may lead to prolonged period of disorder [13, 14] and it would increase relapse rate per annum $[15,16,17]$. Social support maintains synergic role with lithium therapy for this group of patients [18] and would alleviate the relapse risk of depression or mania episodes [19].

Coping styles are intellectual, emotional and behavioral endeavors of individual when confronting with psychological pressure, in order to dominate, endure or minimize the side effects of stress [20].

Suicidal individuals are meaningfully enabled to implement proper coping approaches. These individuals tend to have problems with acquiring information from environment and find suitable solutions [21]. According to sheneidmann (1982), these individuals can not make difference between relevant and irrelevant stressful events and consequently they can not come up with solutions regarding life problematic events [22].

According to Botsis and Colleagues (1994), suicide behavior can be predicted by assessing coping styles [23]. Furthermore, Kotler and Colleagues (1993) showed that individuals who implement maladaptive coping styles tend to commit higher level of suicidal behavior [24]. In another study, Josepho and Plutchrik (1999) assessed roles of coping styles, interpersonal relationship and suicidal behavior; they concluded that suppression maintains positive meaningful correlation with suicidal behavior [25]. Another study postulate that these individuals use blaming and suppression as their main coping styles [26]. Bipolar patients tend to use blaming and denial as their coping mechanism, and aforementioned mechanisms tend to detrimentally affect social function of afflicted [27]; coping styles of bipolar patients demonstrate quality of their symptoms in mania episode [28].

As vital roles of psychological variables were depicted earlier, we conducted current study in order to assess role of social support and coping styles in prediction of suicidal behavior among patient with bipolar disorder type-I. In conclusion, as aforementioned earlier, we couldn't find similar study with predictive outlook in Iran. High morbidity and suicidal trend of this disorder, necessitate conducting current study. Aim of current study is to propose concrete predictive model regarding role of Copying Skill and Social Support with respect to suicide attempt of BD type-I.

\section{Materials and Methods}

One hundred twenty patients were included in our study. We randomly chose our sample from Hazrat-e-Rasoul General Hospital and Iran Psychiatric Hospital were as statistical sample of current study. Bipolar-I diagnosis was confirmed after assessment of psychiatrist via SCID. After acquiring written consent forms, patients answered to Copying Skill Questionnaire (CSQ) and Social Support Questionnaire (SSQ). Obtained data were assessed via Logistic Regression Analysis in SPSS-19.

a. Inclusion Criteria:

1. Confirmed Diagnosis of Bipolar disorder ee-1 via DSM-IV and SCID

2. Age range between $16-25$

3. Fluent Farsi speaking

4. Acquiring written consent form

5. History of suicidal attempt in recent year

b. Exclusion Criteria:

1. Dementia, Psychosis

2. Acute symptoms of Mania or Depression, which tampers with patients responses

Tools:

a. Demographic Questionnaire: We made questionnaire containing demographic data of participants such as, Educational Status, Marital Status, Occupation, Data regarding suicide attempt history (how many times, how, suicidal gesture history and etc.)

b. The Structured Clinical Interview for DSM-IV (SCIDIV): This questionnaire is a semi-structured interview guide for making DSM-IV diagnoses. It is administered by a clinician or trained mental health professional that is familiar with the DSM-IV classification and diagnostic criteria [29]. The validity of a diagnostic assessment technique is generally measured by determining the agreement between the diagnoses made by the assessment technique and some hypothetical "gold standard." Unfortunately, a gold standard for psychiatric diagnoses remains elusive. There is obvious difficulty in using ordinary clinical diagnoses as the standard because structured interviews have been specifically designed to improve on the inherent limitations of an unstructured clinical interview. In fact, a number of studies have used the SCID as the "gold standard" in determining the accuracy of clinical diagnoses [20]. Persian version of this questionnaire has been made by Sharifi and Colleagues (2007) and they have postulated reasonable validity with one week interval of $0 / 95$ [31].

c. Social Support Appraisal Questionnaire (SSA-Q): This psychometric tool investigates of the Social Support Appraisals Scale, a subjective measure of social support, was undertaken with psychiatric inpatients. Good reliability and appropriate subscale intercorrelation were indicated by the data. Evidence of construct validity included significant associations with another social support appraisal measure, measures of 
other social support dimensions, and family-reported data. Strong psychometric properties of the instrument were demonstrated for hospitalized psychiatric patients. Clinical implications for prevention and treatment are discussed [30].

d. Coping Skills Questionnaire has been developed by Moss \& Billings (1981) and included 19 phrase that evaluated two major ways of coping inclusive emotionfocused coping skills with eight and Problem-focused coping skills with eleven phrases. Question 3, 4, 6, 9, $12,15,18$ and 19 relating to the emotion-focused coping and others measure problem-focused coping. Having High scores in each section indicate greater using of that way of coping [42]. Pourshahbaz (1994) reported that validity of coping questionnaire by using of Spearman-Brown formula was 0/78 [43].

After acquiring data, subsequently, we assessed data via
Logistic Regression Analysis in SPSS-19.

\section{Results}

Table 1. Frequency and Frequency Percentage of Suicide Attempts.

\begin{tabular}{lll}
\hline Variable & & Frequency \\
\hline \multirow{2}{*}{ Suicide attempts } & Yes & $(45 \%) 54$ \\
& No & $(55 \%) 66$ \\
\hline
\end{tabular}

In this section, firstly we are going to delineate demographic data with respect to statistical society of current study, after that we are going to assess main hypotheses of this study. Data regarding frequency and frequency percentages in current sample observed on Table 1.

Information regarding demographic data of current sample are shown in Table 2.

Table 2. Demographic characteristics of the Sample.

\begin{tabular}{|c|c|c|c|}
\hline \multirow{2}{*}{ Variable } & \multirow{2}{*}{ Level } & Committed Suicide & Non-Committed Suicide \\
\hline & & $\mathrm{N}=54$ & $\mathrm{~N}=66$ \\
\hline \multirow{2}{*}{ Gender } & Male & $(46.4 \%) 25$ & $(45.5 \%) 30$ \\
\hline & Female & $(53.7 \%) 29$ & $(54.5 \%) 36$ \\
\hline \multirow{4}{*}{ Age Range } & $17-28$ & $(31.5 \%) 17$ & $(16.7 \%) 11$ \\
\hline & $28-39$ & $(35.2 \%) 19$ & $(47 \%) 31$ \\
\hline & $39-50$ & (31.5\%) 17 & $(24.2 \%) 16$ \\
\hline & $50-61$ & $(1.9 \%) 1$ & $(12.1 \%) 8$ \\
\hline \multirow{2}{*}{ Marital Status } & Single & $(41.3 \%) 19$ & $(58.7 \%) 27$ \\
\hline & Married & $(33.3 \%) 14$ & $(66.7 \%) 28$ \\
\hline \multirow{2}{*}{ Occupation } & Employed & $(35.2 \%) 19$ & $(22.7 \%) 15$ \\
\hline & Non-Employed & $(64.9 \%) 35$ & $(77.2 \%) 51$ \\
\hline \multirow{3}{*}{ Educational Status } & Lower than Diploma & $(33.4 \%) 18$ & $(39.4 \%) 26$ \\
\hline & Diploma & $(42.6 \%) 23$ & $(48.5 \%) 32$ \\
\hline & Higher than Bachelor & $(24.2 \%) 13$ & $(12.1 \%) 8$ \\
\hline
\end{tabular}

Table 3. Clinical characteristics of BD patients with and without history of suicide.

\begin{tabular}{|c|c|c|c|}
\hline \multirow{2}{*}{ Variable } & \multirow{2}{*}{ Level } & Committed Suicide & Non-Committed Suicide \\
\hline & & $\mathrm{N}=54$ & $N=66$ \\
\hline \multirow{3}{*}{ Mood Problem Episode } & Mania & $(61.1 \%) 33$ & $(84.8 \%) 56$ \\
\hline & Depression & $(13.6 \%) 9$ & $(13.6 \%) 9$ \\
\hline & Mixed & $(1.9 \%) 9$ & $(1.9 \%) 9$ \\
\hline \multirow{3}{*}{ Hospitalization History } & Once & $(25.9 \%) 14$ & $(18.2 \%) 12$ \\
\hline & Twice & $(13 \%) 7$ & $(27.3 \%) 18$ \\
\hline & Three Times & $(16.7 \%) 9$ & $(22.7 \%) 15$ \\
\hline Self-Harm History & No & $(38.9 \%) 21$ & $(77.3 \%) 51$ \\
\hline
\end{tabular}

Table 4. Number of suicide attempts.

\begin{tabular}{lll}
\hline \multirow{2}{*}{ Variable } & Level & Frequency \\
\cline { 3 - 3 } & One & $\mathbf{N}=\mathbf{5 4}$ \\
\hline \multirow{3}{*}{ Number of suicide } & Twice & $(31.5 \%) 17$ \\
attempts & Three Times & $(16.7 \%) 9$ \\
& More than four & $(27.9 \%) 15$ \\
\hline
\end{tabular}

We obtained data regarding gender, age range, marital status, occupation and educational level. Two groups were accordingly paired and no meaningful difference was noticed between groups. Data regarding clinical characteristics of BD type-I patients with and without history of suicide self-harm history is on Table 3.
Data regarding number of suicide attempts are shown in Table 4.

Data regarding frequency of suicide attempts in firstdegree family members and second-degree family members are seen in Table 5.

According to results of current study, with respect to $1^{\text {st }}$ degree families, sisters tend to be more prone to suicide (each group 4) and method for suicide was taking drugs; with respect to $2^{\text {nd }}$ degree families, aunts (paternal) tend to be more prone to suicide (attempted group: 9, without attempt: 7) and method for suicide was taking firing oneself, and eating toxin. Death in each group was 11 individual in each group, and again aunt possess the highest rate [9]. According to results of current study $74 \%$ of individuals who has 
committed suicide, did it on an impulse and without planning. Sixty three percent had preplanned ideas regarding their suicide; $46.6 \%$ practiced their suicide plans before actually committing it.

Table 5. Frequency of Suicide Attempts in $1^{\text {st }}$ and $2^{\text {nd }}$ degree families.

\begin{tabular}{|c|c|c|c|}
\hline \multirow{2}{*}{ Variable } & & \multirow{2}{*}{$\begin{array}{l}\text { Committed Suicide } \\
\mathrm{N}=54\end{array}$} & \multirow{2}{*}{$\begin{array}{l}\text { Non-Committed Suicide } \\
\mathrm{N}=66\end{array}$} \\
\hline & & & \\
\hline \multirow{2}{*}{ History of suicide attempt in $1^{\text {st }}$ Degree family Member } & Yes & $(24.1 \%) 13$ & $(16.7 \%) 11$ \\
\hline & No & $(75.9 \%) 41$ & $(83.5 \%) 55$ \\
\hline \multirow{2}{*}{ History of suicide attempt in $2^{\text {nd }}$ Degree family Member } & Yes & $(27.8 \%) 15$ & $(18.2 \%) 12$ \\
\hline & No & $(72.7 \%) 39$ & $(81.8 \%) 54$ \\
\hline \multirow{2}{*}{$\begin{array}{l}\text { Death by Committing suicide in } 1^{\text {st }} \text { and } 2^{\text {nd }} \text { degree } \\
\text { family members' }\end{array}$} & Yes & $(16.7 \%) 11$ & $(16.7 \%) 11$ \\
\hline & No & $(76.9 \%) 43$ & $(83.8 \%) 55$ \\
\hline
\end{tabular}

With respect to results of current study, $48 \%$ of participants who had committed suicide had two comorbid conditions (substance abuse disorder, anxiety) in axis-I.
According to Table 6, variables regarding regression model analysis with respect to predicting future suicide attempts are shown in Table 6.

Table 6. Regression Model Analysis with respect to predicting future suicide attempts.

\begin{tabular}{|c|c|c|c|c|c|c|c|c|}
\hline Variable & B & S. E & Wald & Dof & Significance & $\operatorname{Exp}(B)$ & Min & Max \\
\hline Defensive Approaches & $0 / 123$ & $0 / 042$ & $9 / 053$ & 1 & $0 / 003$ & $0 / 881$ & $0 / 81$ & $1 / 95$ \\
\hline Social Support & $0 / 043$ & $0 / 23$ & $3 / 522$ & 1 & $0 / 061$ & $0 / 958$ & $0 / 91$ & $1 / 002$ \\
\hline Constant & $2 / 456$ & $0 / 88$ & $9 / 64$ & 1 & $0 / 002$ & $15 / 73$ & & \\
\hline
\end{tabular}

According to results of current study, it appears plausible that social support can dramatically predict suicide future attempt of bipolar-I patients ( $\mathrm{P}>0.05)$. According to results of current study, with one level enhancement in social support among bipolar-I patients, probability toward suicide attempt would decrease for $0 / 881$. Furthermore, it appears plausible that, coping styles, cannot be used as predictive variables for suicide of Bipolar-I patients.

All in all, according to results of current study, only social support pose prognostic approach toward suicide attempts regarding bipolar-I patients. Clinicians and health authorities should target and precisely evaluate these variables in order to alleviate adverse clinical outcomes and possible future complications regarding this group of patients.

\section{Discussion}

Current study is one of the first studies, which in we discussed roles of social support and coping styles and their relation to suicidal behaviors among BD type-I. According to results of current study, social support tends to be impaired among patient with BD type-I. With the aid of impeccable statistical evaluation we offered quantitative outlook regarding predicting $\mathrm{BD}$ type-I future tendency toward suicide. The result of current study is consistent with the result of study conducted by Durkheim (1951); he postulated that social support maintains inverse role with relation to suicidal behavior [32].

According to various literatures, bipolar patients benefit from lower level of social support and consequently they would face poor therapeutic outcome [33]. Furthermore, social support is vital in order to guarantee remission outcome [34]. Benefiting from supporting role of family members and friends would alleviate the chance of suicidal behaviors; solitude is considered as one of the risk factor consistent with suicidal behavior [35]. Social support is considered as prognostic factor regarding suicidal behavior of non-married or divorced individuals.

Social support is considered as strong predictive tool among healthy individuals as well. In consistent with this concept, Kleinman and liu (2013) reported that argument with family members could increase suicidal behavior trend up to $70 \%$ [36]. Hence it appears plausible that, when problematic social support maintains vital role among healthy people have this valence regarding suicidal behavior, this trend may even be higher among psychiatric patients [19, 33].

It is probable that bipolar patients tend to experience higher level of emotional expression and negative selfassessment, in this sense, when they face negative feedback from family members; they experience higher level of negative emotions [37].

Bipolar patients impulsive and aggressive behavior make their friends and families to feel reluctant to express their love and support toward these patients and indirectly they somehow they get deprived from social support [38].

Having a job is often linked with having prosperous social interactions; hence, it would provide various opportunities regarding initiating social interactions with others [39]. As it can be inferred from various studies, most of these patients are not employed or they have lost their jobs; this would limit their chance regarding receiving social support.

Social support maintains supporting role in treatment of bipolar patients and according to the results of various studies postulate that higher level of social support is accompanied with better and more promising prognosis.

Comparing coping styles of healthy people and suicidal individuals, it has been inferred that former group tend to implement healthier approaches [40]. Furthermore, cognitive abilities of bipolar patients specifically in executive functioning area such as decision making tend to deteriorate as the time goes by [41] and these cognitive deficiencies are 
present both in mania and depression episodes and it is probable that aforementioned deficiencies hinder their ability to express proper coping styles [38]. In current study we hypothesized that inability to implement proper coping styles can serve as predictive role regarding suicidal behavior among bipolar type-1 patients. However, according to regression logistics analysis, coping styles cannot serve as predictive variable regarding suicidal behavior of these patients.

Current sample was consisted of inpatients within the hospital, hence, it appears plausible that patients answered to coping styles questionnaire under influence of symptoms accompanied with the malady. There is another hypothesis as well; maybe coping styles questionnaire can not properly assess coping styles of this group of patients and exclusive questionnaire should be designed and made with respect to this group of patients.

\section{References}

[1] Kessler RC, Bergland P, Demler O, et al. Lifetime prevalence and age-of-onset distributions of DSM-IV disorders in the National Comorbidity Survey Replication. Arch Gen Psychiatry. 2005; 62: 593-602. [PubMed]

[2] Ghaemi SN. Bipolar disorder and antidepressants: an ongoing controversy. Primary Psychiatry. 2001; 8 (2): 28-34.

[3] Michael W. Jann, PharmD. (2014). Diagnosis and Treatment of Bipolar Disorders in Adults: A Review of the Evidence on Pharmacologic Treatments. Available: https://www.ncbi.nlm.nih.gov/pmc/articles/PMC4296286/. Last accessed Feb 2017.

[4] Hirschfeld RMA, Bowden CL, Gitlin MJ, et al. Practice guideline for the treatment of patients with bipolar disorder (revision) [April 14, 2006]; Am J Psychiatry. 2002159 (Suppl): 1-35. Available at:

www.psych.org/psych_pract/treatg/pg/prac_guide.cfm.

[5] Wang, M., Alexanderson, K., Runeson, B., Mittendorfer-Rutz, E. (2015). Sick-leave measures, socio-demographic factors and health care as risk indicators for suicidal behavior in patients with depressive disorders - a nationwide prospective cohort study in Sweden. Journal of Affective Disorders. 173, 201-210.

[6] Sadock, B., Sadock, V., Ruiz, P. (2015). Comperhensive Text Book of Psychiatry. 11th ed. New York: wolters, Lippincott Williams \& Willkins.

[7] Sharifi, V., Amin-Esmaeili, M., Hajebi, A., Motevalian, A., Radgoodarzi, R., Hefazi, M., Rahimi-Movaghar, A. (2015). Twelve-month prevalence and correlates of psychiatric disorders in Iran: The Iranian mental health survey. Archives of Iranian medicine. 18.

[8] Eroglu, M. Z., Karakus, G., Tamam, L., 2013. Bipolardisorderandsuicide. Dusunen Adam. 26 (2), 139-147.

[9] Abreul, N., Lafer, B., Baca-Garcia, E., Oquendo, A. (2009) Suicidal ideation and suicide attempts in bipolar disorder type I: an update for the clinician. Rev Bras Psiquiatr, 31 (3), 27180 .
[10] Cobb, C. (1976). Social support as a moderator of life stress. psychomatic medicine. 38, 300-314.

[11] Studart, P., Galvano-de, A., Bezerra, S., Cavibe, A., Afonso, N., Daltro, A., Scippa, M. (2016). Is history of suicidal behavior related to social support and quality of life in outpatient with bipolar I disorder. Pschiatry Research. 246, 796-802.

[12] Johnson, L., Lundstrom, O., Aberg-Wistedt, A., Mathé, A. A. (2003). Social support in bipolar disorder: its relevant to remission and relapse. Bipolar Disord. 5, 129-137.

[13] Romans, S. E., McPherson, H. M., 1992. The social networks of bipolar affective disorder patients. J. Affect. Disord. 25, 221-228.

[14] Eidelman, P., Gershon, A., Kaplan, K., McGlinchey, E., Harvey, A. G. (2012). Social support and social strain in interepisode bipolar disorder. Bipolar Disord. 14, 628-640.

[15] Nehra, R., Kullhara, P. (1987). Development of a scale for the assessment of social support: Initial try-out in Indian setting. Ind J Soc Psychiatry. 4, 535-539.

[16] Flaherty, J., Moises, F., Black, E., Altman, E., Mitchell, T. (1983). The role of social support in the functioning of patients with unipolar depression. American journal of psychiatry. 140, 473-476.

[17] Johnson, L., Lundstrom, O., Aberg-Wistedt, A., Mathé, A. A. (2003). Social support in bipolar disorder: its relevant to remission and relapse. Bipolar Disord. 5, 129-137.

[18] Oconnel, R., Mayo, J., Eng, L., Jones, J., Gabel, RH. (1985). Social support and long term lithium outcome. Journal of psychiatry. 147, 272-275.

[19] Oddone, C. G., Hybelds, C. F., Mcquoid, D. R., Stteffens, D. C. (2011). Social support modifies the relationship between personality and depressive symptoms in older adults. Am. $J$. Geriatr. Psychiatry. 19 (2), 123-131.

[20] Cohen, F., Lazarus, S. (1979). Coping with the stresses of illness.In: Stoneg, C., Adlern, E., Cohen. Health Psychology. San Francisco, CA: Jossey-Bass, 1979: 217-254.

[21] Lineham, MM, Chiles, JA, Egan, K., Devine, RH. (1986). Presenting problems of parasuicides versus suicide ideators and nonsuicidal psychiatricpatients. JConsult Clin Psychol. $54,880-881$.

[22] SHNEIDMAEN, E. (1982). Voices of death. New York: Harper \& Row.

[23] Botsisa, J., Soldatocs, R., Liossia, A., Kokkevai, A., Stefanis, CN. (1994). Suicide and violence risk. I. Relationship to coping styles. Acta Psychiatr Scand. 89, 92-96.

[24] Kotlemr, M, Finkelstien, G., Molchao, A. (1993). Correlates of suicide and violence risk in an inpatient population: coping styles and social support. Psychiatry Res. 47, 281290.

[25] Josepho, SA, Plutchirk, R. (1994). Stress, coping and suicide risk in psychiatric inpatients. Suicide Life Threat Behav. 24, 48-57.

[26] Horesh, N., Rolnick, T. Iancu, I, Dannon, P., Lepkifker, E., Apter, A., Kotler, M. (1996). Coping styles and suicide risk. Acta Psychiatr Scand. 93, 489-493. 
[27] Lam, D., Wong, G. (1997). Prodromes, coping strategies, insight and social functioning in bipolar affective disorders. Psychol Med. 27, 1091-1100.

[28] Lam, D., Wong, G., Sham, P. (2001). Prodromes, coping strategies and course of illness in bipolar affective disorder - a naturalistic study. Psychol Med. 31, 1397-1402.

[29] APA. (2015). Structured Clinical Interview for DSM-5 (SCID5). Available: https://www.appi.org/products/structuredclinical-interview-for-dsm-5-scid-5. Last accessed Feb 2017.

[30] Kranzler r, Kadden R, Burleson J, et al. Validity of psychiatric diagnoses in patients with substance use disorders - is the interview more important than the interviewer. Compr Psychiat 36: (4) 278-288 Jul-Aug 1995

[31] Vandad Sharifi, MD 1, 2 Seyed Mohammad Assadi, MD 1, 2 Mohammad Reza Mohammadi, MD 1, 2 Homayoun Amini, MD 1, 2 Hossein Kaviani, PhD 1, 2 Yousef Semnani, MD 3 Amir Shabani, MD 4 Zahra Shahrivar, MD 1,. (2007). Structured Clinical Interview for DSM-IV (SCID): Persian Translation and Cultural Adaptation. Available: ijps.tums.ac.ir/index.php/ijps/article/download/435/430. Last accessed Feb2017.

[32] Durkheim, E. (1951). Suicide: A Study in Sociology. Trans. John A. Spaulding and George Simpson. The Free Press, New York.

[33] Johonson, F., Ozdemir, S., Manjunath, R., Hauber, A., Thompson, T. (2007). Factor that effect adeherence to bipolar disorder treatment: a ststed-preference approach. Med Care. $45,545-552$.

[34] Eidelman, P., Gershon, A., Kaplan, K., McGlinchey, E., Harvey, A. G. (2012). Social Support and social strain in interepisode bipolar disorder. Bipolar Disord, 14, 628-40.

[35] Nery-Fernandes, F., Quarantini, L., Guimarães, J. L., Oliveira, I. R., Karestan, K. C., Kapczinski, F., et al. (2012). Is there an association between suicide attempt and delay of initiation of mood stabilizers in bipolar I disorder? J. Affect. Disord. 136, 1082-1087.
[36] Kleinman, E. M., Liu, R. T., (2013). Social support as a protective factor in suicide: findings from two nationally representative samples. J. Affect. Disord. 150, 540-545.

[37] Muralidharan, A., Kotwitcki, R. J., Cowperthwait, C., Craighead, W. E. (2015). Parental relationships and behavioral approach system dysregulation in young adults with bipolar disorder. J. Clin. Psychol. 71 (4), 387-401.

[38] Gruber, S., Rathgeber, K., Braunig, P., Gauggel, S. (2007). Stability and course of neuropsychological deficits in manic and depressed bipolar patients compared to patients with Major Depression. J Affect Disord. 104, 61-71.

[39] Romans, S. E., McPherson, H. M., 1992. The social networks of bipolar affective disorder patients. J. Affect. Disord. 25, 221-228.

[40] Farkhondeh Sharif, PhD; Azam Parsnia, MSc; Arash Mani, PhD; Mehrdad Vosoghi, PhD; Giti Setoodeh, MSc. (2014). Comparison of Personality Traits, Coping Styles, and Psychiatric Disorders in Adult Suicidal and Non-Suicidal Individuals. Available: http://ijcbnm.sums.ac.ir/index.php/ijcbnm/article/viewFile/79/ 47. Last accessed June-2017.

[41] Demant, KM., Almer, GM., Vinberg, M., Kessing, LV., Miskowiak, KW. (2013). Effects of cognitive remediation on cognitive dysfunction in partially or fully remitted patients with bipolar disorder: study protocol for a randomized controlled trial. Trials. 14, 378.

[42] Moss RH, Billings AG. Conceptualizing and measuring coping resources and processes. In: Goldberger L, Brezintz Sh, editors. Handbook of stress: Theoretical and clinical aspects. $2^{\text {nd }}$ ed. Free Press; 1982.

[43] Abasi I, Pourshahbaz A, Mohammadkhani P, Dolatshahi B. Mediation Role of Emotion Regulation Strategies on the Relationship Between Emotional Intensity, Safety and Reward Motivations with Social Anxiety Symptoms, Rumination and Worry: A Structural Equation Modeling, Iran J Psychiatry Behav Sci. Online ahead of Print; In Press (In Press): e9640. doi: 10.5812/ijpbs.9640. 